\title{
The Matrix vs. The Fifth Element-Assessing Future Scenarios of Urban Transport from a Sustainability Perspective
}

\author{
Oliver Kunze and Fabian Frommer *(D)
}

check for updates

Citation: Kunze, O.; Frommer, F. The Matrix vs. The Fifth ElementAssessing Future Scenarios of Urban Transport from a Sustainability Perspective. Sustainability 2021, 13, 3531. https://doi.org/10.3390/ su13063531

Academic Editor: Shailesh Chandra

Received: 22 February 2021

Accepted: 6 March 2021

Published: 22 March 2021

Publisher's Note: MDPI stays neutral with regard to jurisdictional claims in published maps and institutional affiliations.

Copyright: (c) 2021 by the authors. Licensee MDPI, Basel, Switzerland. This article is an open access article distributed under the terms and conditions of the Creative Commons Attribution (CC BY) license (https:// creativecommons.org/licenses/by/ $4.0 /)$.
Institute for Logistics, Risk- and Resource Management (ILR), HNU University of Applied Sciences Neu-Ulm, Wileystraße 1,89231 Neu-Ulm, Germany; oliver.kunze@hnu.de

* Correspondence: fabian.frommer@hnu.de

\begin{abstract}
The future of urban transport (including passenger transportation and goods logistics) may develop in significantly different directions. Depending on changes in urban behavior, and depending on decisions made by lawmakers and governmental bodies, as well as by commercial players, this future may show a significantly reduced mobility of people and goods (for example, as depicted in the motion picture The Matrix, where people live immobilized in cocoons) or a significantly increased mobility (for example, as depicted in the motion picture The Fifth Element, where multiple layers of air traffic are added to road and rail traffic). We applied a systems thinking method to create a model for political decision makers and researchers. This model can contribute to a better understanding of the interrelations of societal factors (e.g., behavioral changes in the current COVID-19 situation), technological factors (e.g., the role of data traffic or emerging urban air traffic) and environmental factors (e.g., noise or $\mathrm{CO}_{2}$ emissions) in an urban mobility and logistics system. The research also shows that data traffic has the potential to partially substitute physical passenger and goods traffic under certain circumstances. Thus, data networks should conceptually be regarded as a new mode of transport that plays a role in the urban modal split.
\end{abstract}

Keywords: delivery; distribution; emissions; environment; freight; logistics; mobility; modeling; sustainability; technologies; traffic; urban

\section{Introduction}

It is uncertain how urban traffic will develop in the future. Whilst urban traffic seems to be growing in general, it can be observed that external factors, such as the current COVID-19 situation, may lead to an unexpected decrease in urban traffic.

The two motion pictures, The Matrix (director: the Wachowskis, starring: Keanu Reeves, Carrie-Anne Moss, et al., 1999) and The Fifth Element (director: Luc Besson, starring: Bruce Willis, Milla Jovovich, et al., 1997), each depict quite different visions of a distant urban future with respect to mobility and traffic. Whilst The Matrix envisions a completely immobilized humanity (in which humans are locked into cocoons, physically sustained via tubes and linked into a virtual reality universe that emulates all sensations), The Fifth Element envisions a highly mobilized humanity (moving around by traditional means of transport like cars, taxis, trains, etc., as well as by individual airborne vehicles in a multiple layer air-corridor system). Thus, the two films metaphorically depict opposite ends of an urban mobility and traffic spectrum.

In today's real world, new technological developments (such as autonomous vehicles and ground drones, air drones, virtual reality, 3D printing, etc.) and new societal developments (e.g., changing patterns in shopping behavior, the COVID-19 pandemic, the Fridays for Future movement, etc.) contribute to shaping urban logistics and mobility concepts, as well as the resulting urban traffic of tomorrow.

Whichever mobility and logistics concepts prevail, their real-life implementation will have a twofold impact-(a) on urban traffic and (b) on the urban (and global) environment. 


\subsection{Research Questions}

As private companies shape this future whilst attempting to maximize profits, governmental and legislative bodies should understand the mid- and long-term environmental implications of such concepts in order to make decisions with respect to legislative regulations, as well as with respect to funding of subsidy programs.

Thus, the research questions addressed in this study were: (1) What emerging logistics and mobility concepts can be detected today? (2) What new types of traffic will be induced by their implementation? (3) What environmental impacts will their implementation generate?

As the term "new concepts" is a very general one, in this context it was interpreted as "concepts related to transport modes and means of transport".

\subsection{New Transport Modes}

Research question (1) (What emerging logistics and mobility concepts can be detected today?) was answered by a non-exhaustive, commented literature overview.

\subsubsection{Data}

Data traffic is the "elephant in the room" of traffic models. The fact that worldwide data traffic is growing is commonsense knowledge. However, we suggest understanding data as a new alternative mode of transport because it has the potential to substitute the mobility needs of humans, as well as transport logistics volumes.

As can be seen in the current COVID-19 situation, data traffic may substitute business as well as private trips. Video conferences reduce the need for business travel, meeting friends via video conferences helps humans to escape social isolation, online shopping substitutes for a significant part of shopping activities, streaming services reduce the need to go to the movies, and immersive virtual reality (VR) and (online) video games turn out to be a substitute for meeting friends-especially for the young generation of digital natives.

In the world of logistics, additive manufacturing (AM), i.e., 3D printing (3DP), may turn out to be a disruptive technology as it has the potential to substitute a large amount of goods transport with data transport to local 3D printers, even taking into account the fact that the raw print materials (e.g., filament, powder or resin) need to be transported to the printers earlier. However, as the raw print material is not itemized prior to transport, raw print material transports alone would result in significantly lower goods traffic than the transport of all individually printed items via classical resale channels due to scale effects.

Scientific publications in this domain seem to be developing. Taniguchi et al. [1] and Silva and Rezende [2] examined the potential of 3DP in future logistics. Cerdas et al. [3] assessed the ecological impacts of 3D printing in a distributed manufacturing system using lifecycle assessment. Still, the impact of 3DP on traffic seems to need further research.

In a nutshell: The (partial) substitution of physical passenger and goods traffic by data traffic can metaphorically be interpreted as a move towards the "Matrix" end of the mobility and traffic spectrum.

\subsubsection{Air}

While companies, lawmakers, regulative bodies and some researchers are developing air traffic as a new mode of urban transport, surprisingly this ongoing process seems not to be largely noticed by the general public. In Europe, the EU is preparing a dedicated air space for the operation of unmanned aerial vehicles (UAVs-also called air drones) called U-space (see, e.g., [4,5]). Once operative, air will most likely become a new urban mode of transport in European cities.

Scientific publications in this domain are growing. Fu et al. [6] examine potentials and applications of urban air mobility in Munich. Shamiyeh et al. [7] present a performance benchmark of recent personal air vehicle concepts for urban air mobility. Vascik and Hansman [8] examine the constraints of urban air mobility with a special focus on noise 
emissions. Besides passenger transport, the mode air can also be used as a new mode of transport for goods. In this context, the concept of drone delivery is examined in the existing literature. Carlsson and Song [9], as well as Scott and Scott [10], evaluate the potentials of drone logistics (e.g., in the healthcare sector). Koiwanit [11] and Figliozzi [12] examine ecological aspects of drone delivery systems using life cycle assessment.

In a nutshell: Provided that the new transport mode air will excessively be used by passengers and by logistics service providers, this shift can be interpreted as a move towards the "Fifth Element" — end of the mobility and traffic spectrum.

\subsubsection{Aerial Cable Cars}

Another innovative concept for urban mobility deals with urban aerial cable cars (or metro-cable) and is implemented, for example, in Medellin (see Brand and Dávila [13]) and Bogota (see Oviedo and Guzman [14]). "Aerial cable cars ... have recently become a best practice for urban integration of urban communities challenged by steep topographies and a systematic lack of good-quality mobility services ... " [14]. This concept has been implemented in other urban communities, too, e.g., in London (GB), Moscow (RUS), or Sarajevo (BIH) [15], and it is being considered, for example, for Amsterdam (NL), Cologne (D), Frankfurt/Main (D), Gothenburg (SE), Munich (D), [15] or Graz (Austria) [16].

Although this mode is mainly designed for passenger transport, it can also be used for last-mile goods distribution in a crowd logistics context.

\subsubsection{Pipelines}

Pipeline systems such as, for example, Hyperloop or Cargo Sous Terrain are being discussed as a new transport mode for goods- and/or passenger-transport (see, e.g., Markvica et al. [17]). Hansen [18] and Werner et al. [19] assess the deployment of the Hyperloop for passenger and goods transport in the pipeline. Stein and Schoesser [20] examine new technologies for urban goods transport and, therefore, focus on CargoCap, which poses a subterranean pipeline freight transport system. Visser [21] examines similar concepts.

Anyhow, due to significant infrastructure construction costs and their capacity to transport large volumes over long distances, these systems are likely to be used for intercity goods transports rather than for last-mile intra-city transports.

\subsubsection{Sideways Used by Ground Drones}

Sideways are usually not considered to represent a "new" mode of transport, because they are a very established "old" mode for passenger traffic. However, sideways gradually may become a new mode of transport for goods, if the concept of "ground drones" (often also termed "robots" or "droids" or sideway-based unmanned ground vehicles UGVs) becomes more popular in urban logistics. Ground drones maximally drive at a pedestrian's speed and thus are designed to operate on sideways. This concept is commercially propagated, for example, by Starship Technologies (www.starship.xyz, accessed on 1 March 2021), which has implemented a large-scale field trial at Milton Keynes (GB), and which currently transports COVID-19 test kits to private homes in parts of Hamburg (GER) [22]. Still, up to now, ground drones on sideways are not frequently discussed in the scientific world, yet, even if street-based autonomous ground vehicles are considered by the scientific world as, e.g., in [23].

A non-exhaustive overview of the literature on emerging transport modes is given in Figure 1. This overview shows that transport modes usually are discussed either from a passenger's or from a good's perspective. It also shows that data as a dedicated mode has not explicitly been established yet. 


\begin{tabular}{|c|c|c|c|c|c|c|c|c|c|}
\hline \multirow[b]{2}{*}{ Source: } & \multicolumn{2}{|c|}{ Scope (Traffic) } & \multirow[b]{2}{*}{ Air } & \multicolumn{3}{|c|}{ Scope ("New" Mode) } & \multicolumn{3}{|c|}{ Scope (Environment) } \\
\hline & Passengers & Goods & & Data & Pipeline & Cable-Car & Air & Energy & Noise \\
\hline Hansen 2020 & $\square$ & & & & $\square$ & & & & \\
\hline Fu et al. 2019 & $\nabla$ & & $\nabla$ & & & & & & \\
\hline Shamiyeh et al. 2018 & $\nabla$ & & $\nabla$ & & & & & & \\
\hline Vascik and Hansman 2018 & $\nabla$ & & $\nabla$ & & & & & & $\square$ \\
\hline Carlsson and Song 2018 & & $\nabla$ & $\nabla$ & & & & & & \\
\hline Koiwanit 2018 & & $\nabla$ & $\nabla$ & & & & $\square$ & $\nabla$ & \\
\hline Visser 2018 & & $\nabla$ & & & $\square$ & & & & \\
\hline Cerdas et al. 2017 & & $\nabla$ & & $(\checkmark) 3 \mathrm{DP}$ & & & $\nabla$ & $\square$ & \\
\hline Huang et al. 2017 & & $\nabla$ & & $(\vee) 3 \mathrm{DP}$ & & & & & \\
\hline Figliozzi 2017 & & $\nabla$ & $\square$ & & & & $\square$ & $\nabla$ & \\
\hline Scott and Scott 2017 & & $\nabla$ & $\nabla$ & & & & & & \\
\hline Werner et al. 2016 & & $\nabla$ & & & $\nabla$ & & & & \\
\hline Taniguchi et al. 2016 & & $\nabla$ & & $(\checkmark) 3 \mathrm{DP}$ & & & & & \\
\hline Silva and Rezende 2013 & & $\nabla$ & & $(\vee) 3 \mathrm{DP}$ & & & & & \\
\hline Stein and Schoesser 2012 & & $\nabla$ & & & $\square$ & & & & \\
\hline Brand and Dávila 2011 & $\square$ & & & & & 甲 & & & \\
\hline \multirow{2}{*}{ Legend: } & & included & & & & & & & \\
\hline & $\begin{array}{l}\square \\
(\checkmark)\end{array}$ & $\begin{array}{l}\text { included } \\
\text { partly con }\end{array}$ & ered & & & & & & \\
\hline
\end{tabular}

Figure 1. Overview of emerging transport modes.

\subsection{New Concepts for Existing Modes of Transport}

Besides new modes (and new means) of transport, existing scientific literature also focuses on other new innovative mobility concepts for passenger and goods transport, two of which we consider relevant for the research questions.

\subsubsection{Crowd Logistics}

Crowd logistics is an emerging concept that needs to be considered in this context. "Within crowd logistics (CL), delivery operations are carried out by using passengers' excess capacity on journeys that are already taking place, resulting in economic, social and environmental benefits." ([24] ( $\mathrm{p} 1)$ ). Thus, crowd logistics could be interpreted as a "meta mode of goods transport" in the sense of "backpack riding".

Scientific publications in this domain are developing. Buldeo Rai et al. [24] and Sampaio et al. [25] describe the concept of crowd logistics, which uses the crowd to deliver packages within cities (especially on the last mile). Crainic and Montreuil [26] present the concept of the physical internet (PI), which can be interpreted as a general framework that encompasses, for example, urban crowd logistics as one possible implementation of (a local) PI.

\subsubsection{Modified Land Use and Other Concepts}

One cluster of literature consists of concepts aiming at sustainable urban mobility that combine land-use and urban transport (e.g., Banister [27], Banister [28], Bertolini et al. [29], Bertolini and Le Clercq [30], Kenworthy [31], and Wulfhorst et al. [32]). Banister [27] presents a sustainable urban mobility paradigm. Banister [28] and Bertolini et al. [29] propose concepts to improve urban accessibility by coordinating land-use and transport. Bertolini and Le Clercq [30] and Wulfhorst et al. [32] present policy concepts for sustainable urban mobility with fewer cars.

Other innovative mobility concepts currently examined in the scientific literature are autonomous driving (e.g., Pavone [33]) and shared mobility (e.g., Machado et al. [34]), to name but a few.

A non-exhaustive overview of the literature on innovative urban traffic concepts is given in Figure 2. This overview again shows a clear separation of concepts related to either passengers or goods. 


\begin{tabular}{|c|c|c|c|c|c|}
\hline \multirow[b]{2}{*}{ Source: } & \multicolumn{2}{|c|}{ Scope (Traffic) } & \multicolumn{3}{|c|}{ Scope (Environment) } \\
\hline & Passengers & Goods & Air & Energy & Noise \\
\hline Sampaio et al. 2019 & & $\square$ & & & \\
\hline Machado et al. 2018 & $\nabla$ & & & & \\
\hline Wulfhorst et al. 2017 & $\nabla$ & & $(\checkmark)$ & $(\checkmark)$ & \\
\hline Buldeo Rai et al. 2017 & & $\square$ & $(\checkmark)$ & $(\checkmark)$ & \\
\hline Crainic and Montreuil 2016 & & $\nabla$ & & & \\
\hline Pavone 2015 & $\square$ & $(\checkmark)$ & & & \\
\hline Banister 2011 & $\nabla$ & & $(\checkmark)$ & & \\
\hline Banister 2008 & $\nabla$ & & & & \\
\hline Kenworthy 2006 & $\nabla$ & & $(\checkmark)$ & $(\checkmark)$ & $(\checkmark)$ \\
\hline Bertolini et al. 2005 & $\nabla$ & & $(\checkmark)$ & $(\checkmark)$ & $(\checkmark)$ \\
\hline Bertolini and Le Clercq 2003 & $\nabla$ & & $(\checkmark)$ & $(\checkmark)$ & $\square$ \\
\hline \multirow[t]{2}{*}{ Legend: } & $\square$ & included & & & \\
\hline & $(\checkmark)$ & \multicolumn{2}{|c|}{ partly considered } & & \\
\hline
\end{tabular}

Figure 2. Overview of selected innovative traffic-related concepts.

\section{Materials and Methods}

Whereas the answer to the research question (1) can, for example, be generated by literature research (see Section 1), it is to be decided which methodology can generate answers to the research questions (2) and (3).

In the literature, multi-factorial modeling of mobility is reported. Priester et al. [35] create a systems thinking model to describe and evaluate developments towards sustainable urban mobility. Kunze et al. [36] apply systems thinking to city logistics, and Kunze [37] uses the systems thinking approach to examine future scenarios of urban logistics.

Other authors use a system dynamics approach to model urban mobility (e.g., Melkonyan et al. [38], Fontoura et al. [39], and Del Vecchio et al. [40]). Melkonyan et al. [38] and Fontoura et al. [39] both use their approach to evaluate mobility policies. Del Vecchio et al. [40] examine the system of smart mobility.

Another subject of investigation is the macroscopic modeling of mobility and traffic. Helbing et al. [41] present a mathematical macroscopic traffic model. Doniec et al. [42] describe a multi-agent-based model with a behavioral approach, and Xia et al. [43] analyze big urban traffic data to characterize urban mobility using vehicular social networks.

A brief overview of these approaches is given in Figure 3 and illustrates the differences in model scope and methodology. This non-exhaustive literature overview shows that several authors create different multi-factorial models of urban mobility, traffic, and transport using qualitative and quantitative model types. Again, passenger transport and goods transport are usually considered separately. It is to be noted that these models seldomly encompass new modes of transport. They mostly deal with today's modal reality and not with the possible modal realities of tomorrow.

For these reasons, a research gap is identified in connecting individual new modes of transport, new means of transport, and new mobility concepts to a more holistic systemmodel, which also includes impacts on the environment. 


\begin{tabular}{|c|c|c|c|c|c|c|c|}
\hline \multirow[b]{2}{*}{ Source: } & \multicolumn{2}{|c|}{ Model Scope (Traffic) } & \multicolumn{3}{|c|}{ Model Scope (Environment) } & \multicolumn{2}{|c|}{ Model Type } \\
\hline & Passengers & Goods & Air & Energy & Noise & Qualitative & Quantitative \\
\hline Melkonyan et al. 2020 & $\nabla$ & & $(\checkmark)$ & $(\checkmark)$ & & & 凶 \\
\hline Del Vecchio et al. 2019 & $\nabla$ & & & $(\vee)$ & & & 凶 \\
\hline Fontoura et al. 2019 & $\nabla$ & & $(\vee)$ & $(\sqrt{ })$ & & & $\mathbf{x}$ \\
\hline Xia et al. 2018 & $\nabla$ & $(\vee)$ & & & & & 凶 \\
\hline Kunze 2016a & & $\square$ & $\square$ & & $\square$ & 凶 & \\
\hline Kunze et al. 2016b & & $\nabla$ & $(\checkmark)$ & $(\vee)$ & $(\checkmark)$ & $\mathbf{x}$ & \\
\hline Priester et al. 2014 & $\square$ & & $(\checkmark)$ & $(\vee)$ & $(\vee)$ & 凶 & \\
\hline Doniec et al. 2008 & $\nabla$ & & & & & & 凶 \\
\hline Helbing et al. 2001 & $\square$ & $(\checkmark)$ & & & & & $\mathbf{x}$ \\
\hline \multirow[t]{2}{*}{ Legend: } & $\square$ & included & & & & 凶 & model type \\
\hline & $(\checkmark)$ & \multicolumn{2}{|c|}{ partly considered } & & & & \\
\hline
\end{tabular}

Figure 3. Overview of selected models.

\subsection{Systems Thinking Approach}

While the assessment of future developments is a difficult problem (even if it is only conducted from a non-detailed, top-level perspective), the choice of a methodology for such assessments is a difficult problem in itself. The key aspects of the choice of the methodology are adequacy (i.e., the method shall contribute to the attempt to answer the research question), falsifiability (i.e., it shall be possible to falsify results provided by the method), completeness (i.e., the method shall transparently cover the relevant aspects and also show which aspects are neglected) and data availability (i.e., a methodology which cannot be filled with the required data will not be able to generate the desired answers to the research question).

Considering these aspects, we chose the systems thinking concept introduced by Vester [44] as the basis for our methodology for the following reasons:

1. Adequacy: Systems thinking was designed for the analysis of complex systems.

2. Falsifiability: It fulfills the falsification criterion of Popper and Camiller [45] (pp. 10-11).

3. Completeness: Systems thinking positively describes what is considered (and what not); thus, it provides a basis for critical discussions on whether the selected aspects are sufficiently complete or whether significant aspects are missing.

4. Data Availability: As it is a top-level, qualitative and not a detail-level, quantitative methodology, the problem of missing numerical data is not critical.

A straightforward, quasi-linear subset of the model building steps suggested by Vester [44] was applied. This quasi-linear methodology is depicted in Figure 4.

We want to point out that even if the methodology seems quite linear, we conducted several iterations of this linear process (see the backward path in Figure 4) until initial implausibilities and gaps were removed from the effect system. Thus, we call this methodology quasi-linear.

We also want to point out that, according to Popper's scientific theory, it is impossible to validate models, but it is possible to falsify models. Thus, we will now explain each of the methodological steps, decisions, and choices we applied to build a most robust basis for falsification of our model. We present this model to the scientific community for critical assessment and improvement. 


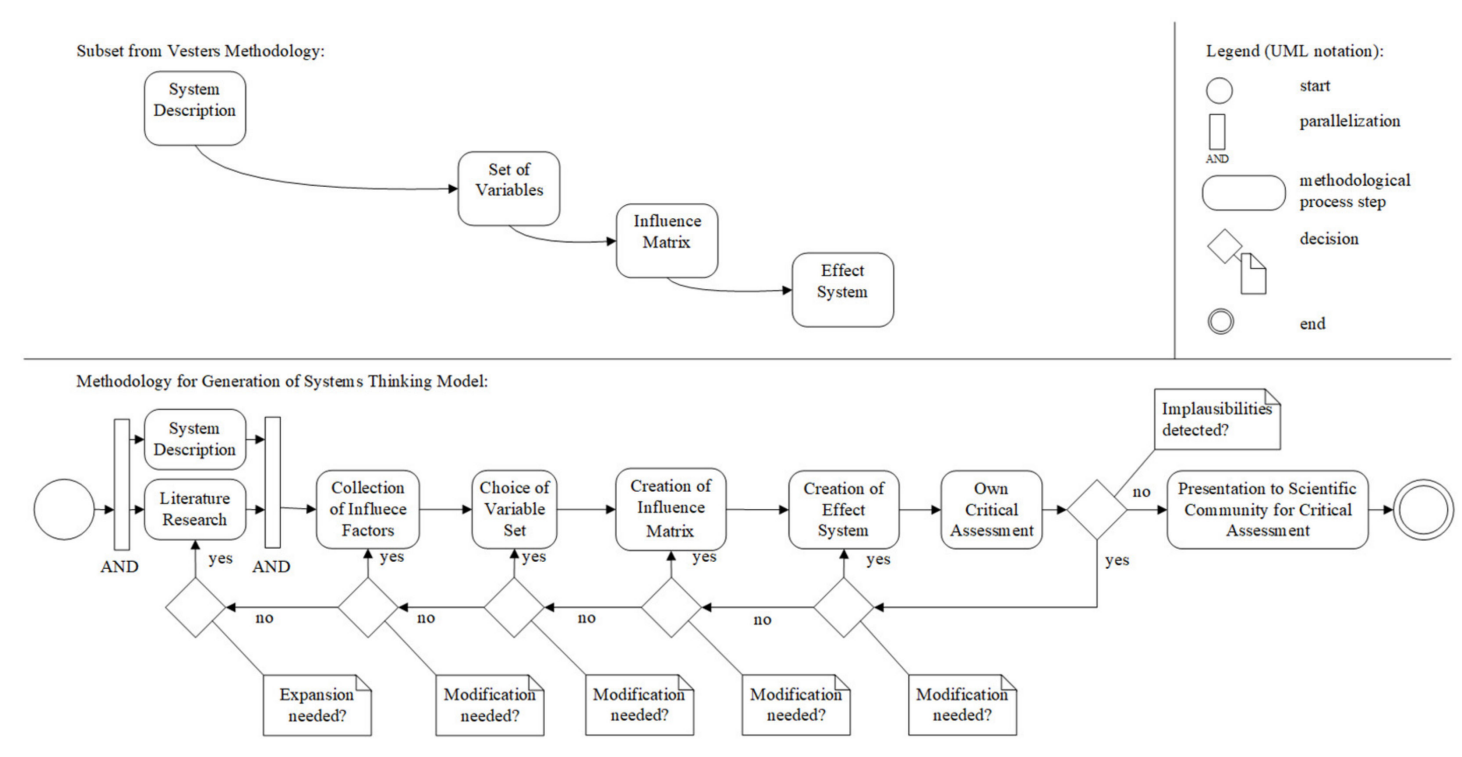

Figure 4. Methodology overview.

In an initial step, the system description was built based on the research questions (2) and (3). The key assumptions for the system are:

- The land use of the city is static-i.e., we assume, that a city and its geographical structure regarding activities (e.g., living, work, school, shopping, spare time) is given (see grey elements in Figure 5). This is a significant assumption, but it is motivated by the fact, that the layout of a city will only gradually change over long periods.

- Modes of traffic and means of transport can be changed-i.e., by adding new modes and means of transport, traffic and the impact on the environment will change.

- Behavior patterns of citizens need to be considered at least on a less-detailed granularity level.

The visualization of the system description (as suggested by Vester) is shown in Figure 5. Parallel to the creation of this system description, a first literature research was conducted, which was later expanded within the iterative model building process (see the backward path in Figure 4). Based on the literature research results (see Section 1) and on the system description, a set of possible influence factors was collected, which formed the basis for the choice of the set of variables.

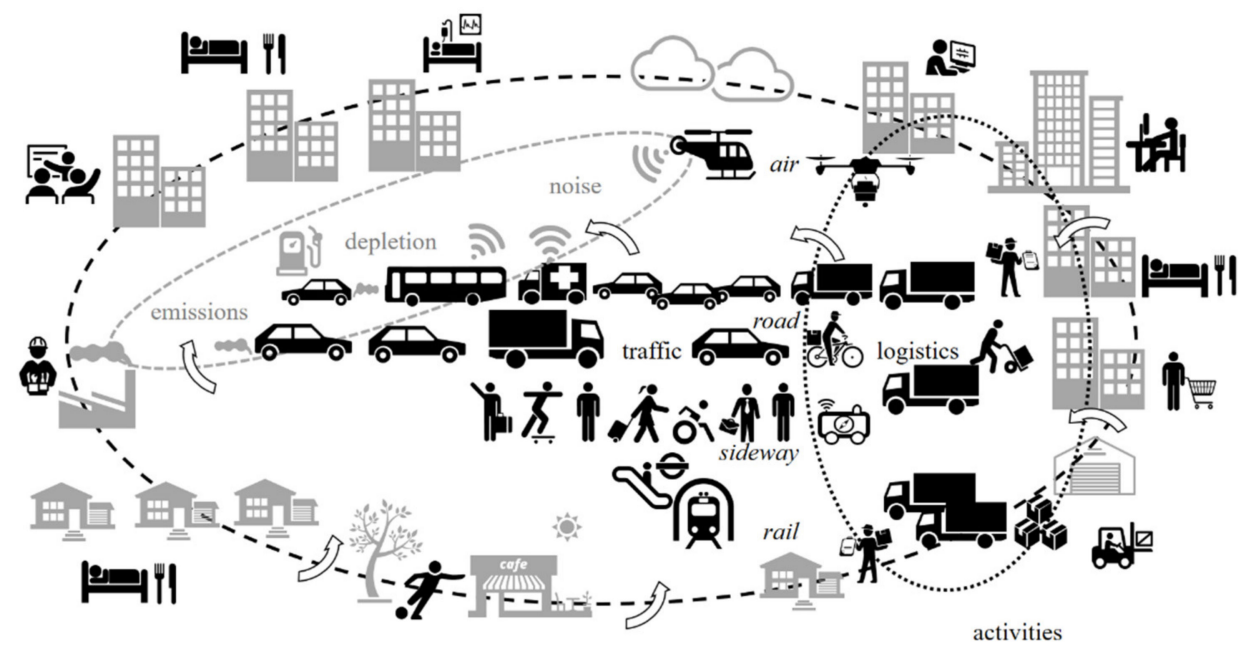

Figure 5. Visual system description. 


\subsection{Set of Variables}

The choice of the set of variables (or factors) is crucial for the systems thinking model design. As the model shall help to understand new transport modes and new means of transport and their ecological impacts, "traffic" and "ecological impacts" are two mandatory factor sets for our model. Model entities to represent "transport logistics services" are also needed, as they generate goods traffic. Finally, we decided to include "mobility and logistics demand" entities that shall represent the urban activities of humans.

\subsubsection{Mobility and Logistics Demand}

Where does the need to transport goods and passengers stem from in an urban context? The need to transport passengers stems from their mobility needs (see Figure 5) -i.e., the need to go to work, to school, go shopping, go to places where they can spend their spare time, or the need to go to other places (e.g., hospitals, court, etc.). We will focus our model on office work, schooling, leisure, and shopping, as theoretically these activities could be performed at home, too. Other activities (see grey elements in Figure 6) were ignored in our model because they cannot be performed at home.

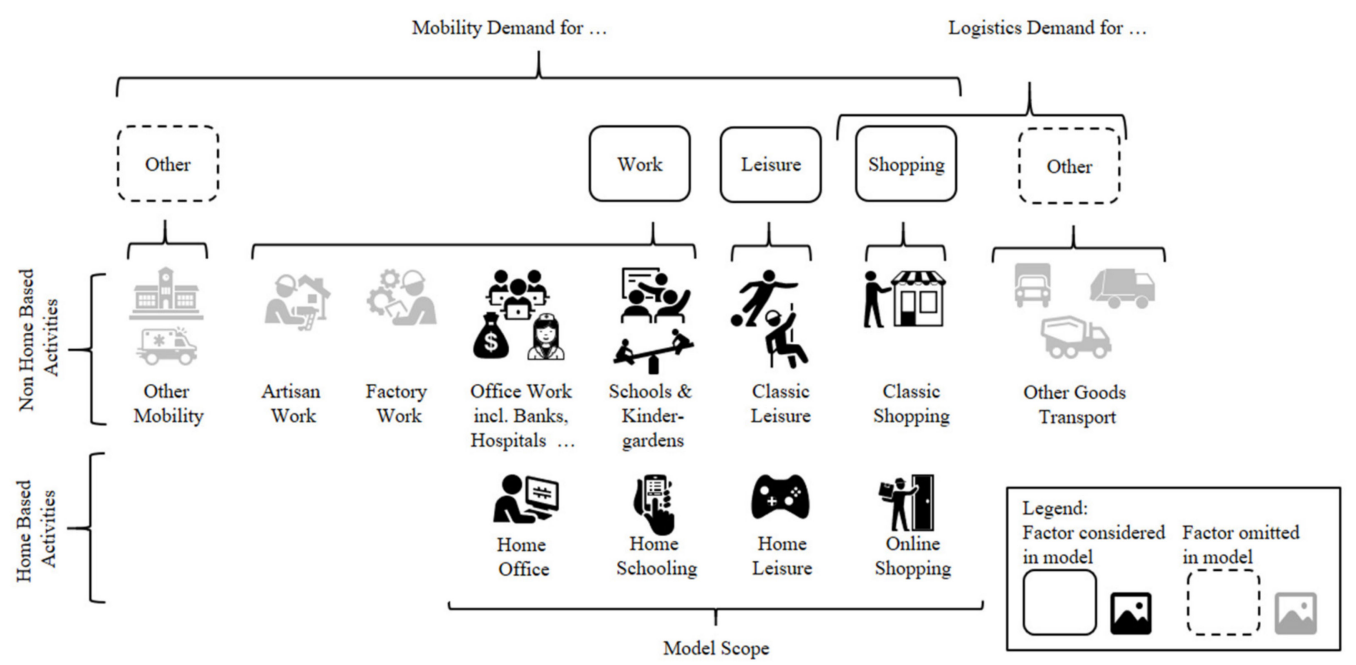

Figure 6. Mobility and logistics demand.

The need to transport goods is also quite diverse (e.g., construction material needs to be transported to construction sites, waste needs to be collected, heating oil needs to be distributed) but a significant part of goods transports is related to retail, i.e., shop replenishment and home delivery.

In our model, we focus on the non-exceptional mobility demand and on the logistics demand, which stems from retail (excluding other logistics operations such as relocation services, construction site deliveries, waste collection, etc.). We also suggest differentiating between home-based activities (including online shopping) and non-home-based activities, as they have a different impact on traffic.

\subsubsection{Transport Logistics Services}

Today most transport logistics services use vans or trucks. However, currently a larger number of different new options to provide logistics transport services are being discussed and are emerging ([37] (pp. 286-299)). For instance, bike-delivery services have become more popular, and crowd and drone logistics services are being tested. These new service concepts also have the potential to use different modes of transport, and thus they have the potential to shift commercial traffic from roads to other transport modes. Figure 7 shows an overview of potential logistics services and concepts—differentiated by transport modes and means of transport. 


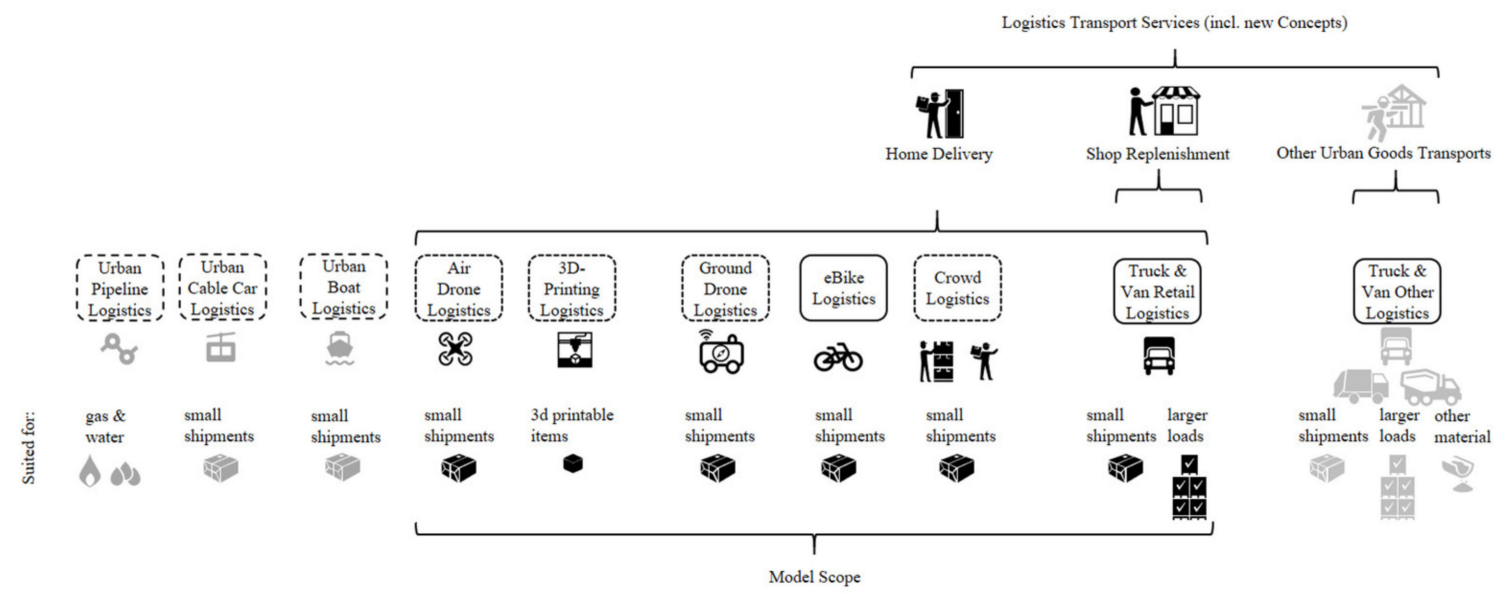

Figure 7. Logistics services (and concepts).

Not all new services may transport all types of goods, but most of them could transport small shipments (e.g., small parcels). One especially interesting logistics transport service is $3 \mathrm{D}$ printing because it has the potential to largely substitute the physical transports of items by the transport of digital twins (i.e., 3DP-construction data) to the local printer.

In our model, we focus on services that can (a) transport smaller shipments to a multitude of urban destinations (thus, pipeline logistics are excluded) and which (b) are potentially available in every city without the need to have or build new infrastructures (thus, waterway logistics and cable car logistics are excluded).

\subsubsection{Traffic}

Urban traffic needs to be differentiated by transport mode if modal shifts are to be considered. Figure 8 shows an overview of the different emerging and existing urban transport modes.

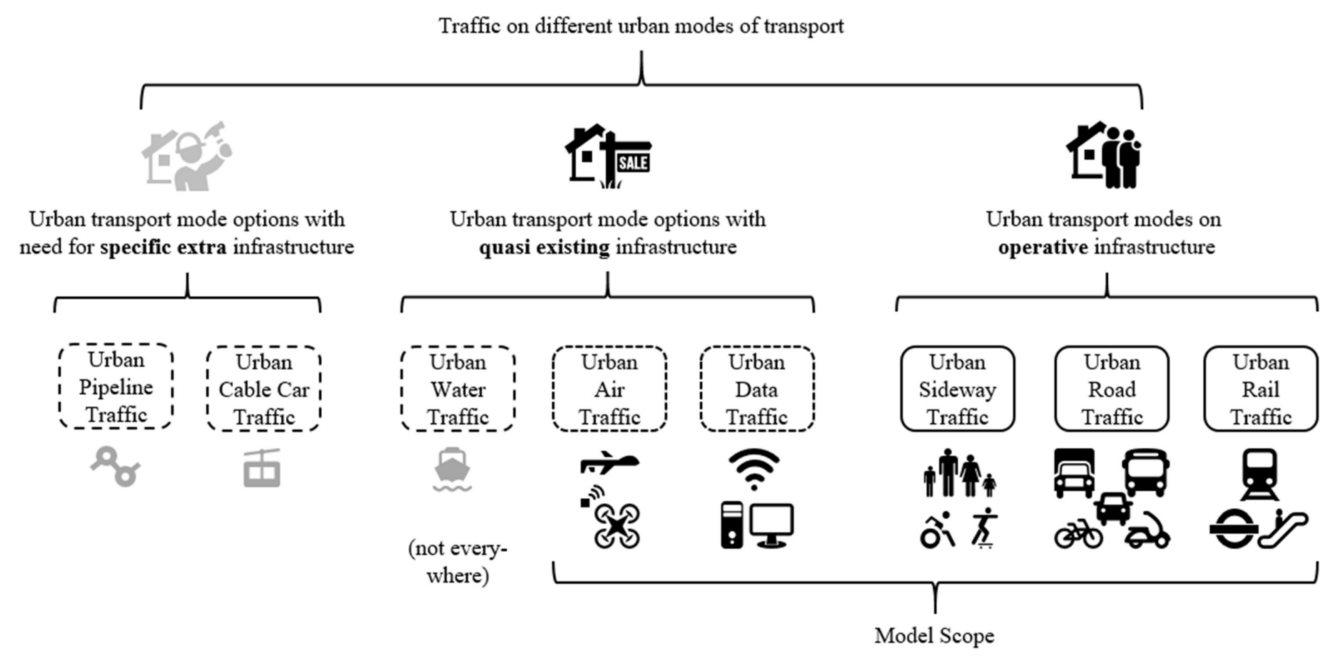

Figure 8. Emerging and existing urban transport modes differentiated by infrastructure prerequisites.

If only existing modes are considered, no new modal developments can be considered. If, on the other hand, all possible modes are considered, some "exotic" modes may get too much attention. Therefore, we needed to make a choice, which traffic modes we want to include in our model. Thus, we reason, that "mode availability" is a top-level criterion to cluster and assess existing and emerging new modes, and clustered them into three categories: 
1. Modes with operative infrastructure-i.e., the infrastructure exists in almost every urban context and is operationally used. Here, we included today's existing urban transport modes (road and rail) and added sideway traffic (which is often neglected, but we consider sideway traffic to represent an interesting mode for logistics-co-use, e.g., by ground drone transports and crowd logistics transports).

2. Modes with quasi-existing infrastructure-i.e., infrastructure, which generally speaking is already there in most urban areas, but which is not "ready to use" yet, because functional nodes (stations, hubs) are currently still missing. Here, we added water traffic (which is not available in many cities, due to the lack of waterway systems), air traffic (which currently is strongly promoted by the drone lobby), and data traffic.

3. Modes requiring specific extra infrastructure-i.e., infrastructure, which still needs to be built.

For our model, we excluded those traffic modes which would require significant infrastructure investments. We also excluded waterways as a mode of transport, because they are not available in every city. Thus, the two new "promising" traffic types we consider in our model are data traffic and air traffic.

\subsubsection{Ecological Impacts}

In our model, we focus on the key traffic-related ecological impacts (i.e., global $\mathrm{CO}_{2}$ emissions, local particle emissions, noise emissions, and fossil energy depletion). We also modeled electrical energy consumption as a mediating factor for fossil energy depletion because electric energy can also be generated by means of nuclear or sustainable energy sources (for details, see Figure 9).

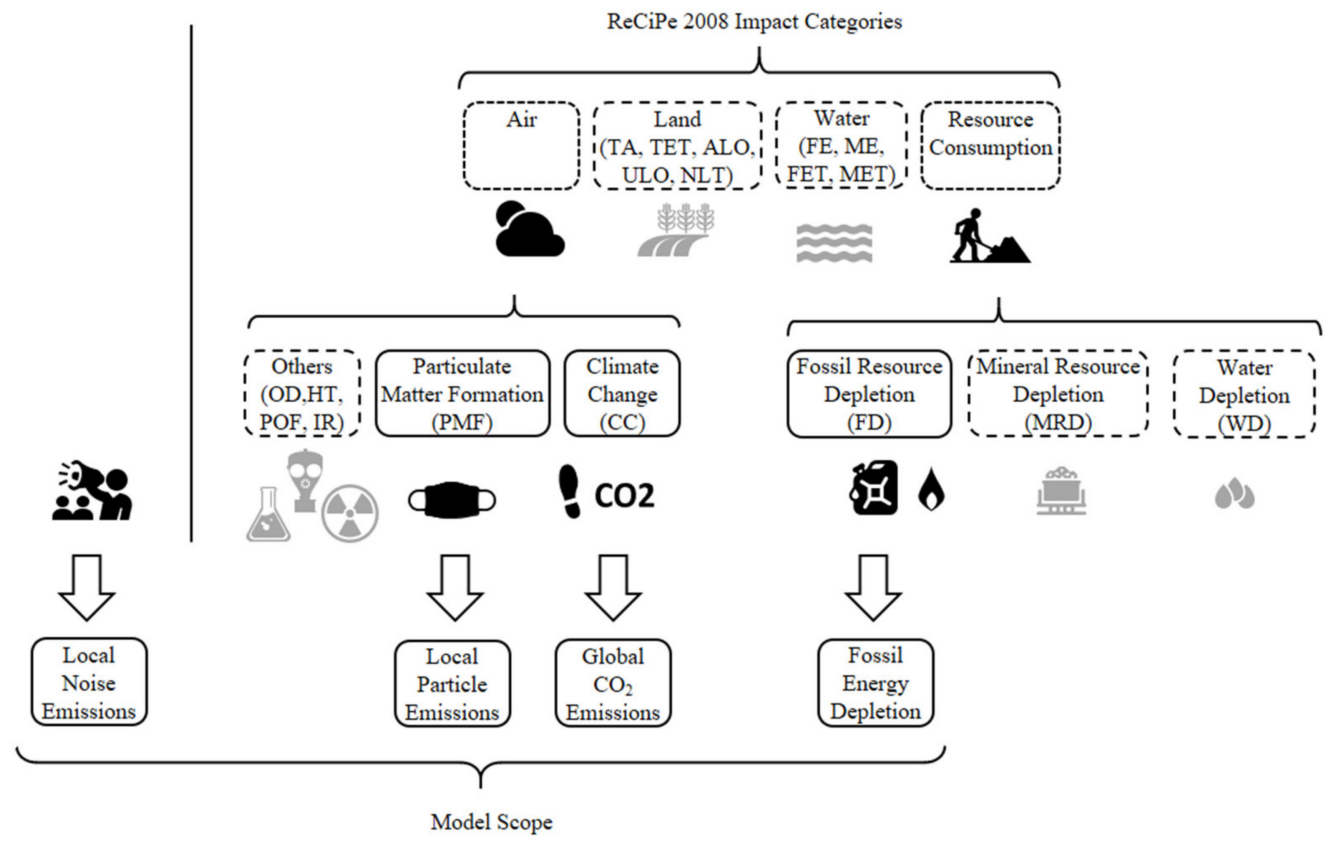

Figure 9. Considered ecological impact assessment criteria.

Still, there are ecological impacts which might go unobserved. Thus, we also want to point out which aspects are not considered by our model. To illustrate which aspects are covered and which are missing, we used the concept of impact categories (as defined in the ReCiPe 2008 method-see [46] (p. 7)) as a benchmark. These categories are implicitly structured in four ecological impact clusters: Air (climate change, CC; ozone depletion, OD; human toxicity, HT; photochemical oxidant formation, POF; particulate matter formation, PMF; ionizing radiation, IR), Land (terrestrial acidification, TA; terrestrial ecotoxicity, TET; agricultural land occupation, ALO; urban land occupation, ULO; natural land transformation, NLT), Water (freshwater eutrophication, FE; freshwater ecotoxicity, FET; marine 
eutrophication, ME; marine ecotoxicity, MET) and Resource Consumption (water depletion, WD; mineral resource depletion, MRD; fossil resource depletion, FD). Figure 9 depicts a graphical comparison of the ReCiPe 2008 impact factors and the factors considered in our model.

This criterion selection was mostly based on the fact that we wanted to keep the model complexity at bay. We want to point out one important implication of this choice: leaving out rare-earth and lithium resource depletion (as part of MRD) which is induced, for example, by battery electric vehicles, is an uncovered aspect in our model and thus requires further research. This example shows that our model cannot say which transport alternatives are ecologically better in general, but only which are better with regard to the selected four ecological impact factors within our model.

\subsubsection{Other Factors}

The above factor (or variable) selection for the model might be disputed-but it provides a positive list of factors considered and, probably even more important, which factors are not considered.

Due to the current COVID-19-Situation, we added one more factor to our model which we call "pandemic wake". It shall model the (previous to the outbreak mostly unpredicted) shifts in urban transportation demand due to the threat of the virus.

We assume, that there may be other factors like the pandemic wake which could impact the socio-sphere and other factors related to the techno- or eco-sphere. However, in our model, such factors are not included.

\subsection{Influence Matrix and Effect System}

Now that we have established the set of factors for our model, we want to introduce the influence matrix and the effect system-i.e., the model of how strongly the modeled factors are interrelated (or have an effect on each other). Vester [44] (pp. 219-225) suggests to use the values $\{0,1,2,3\}$ to indicate if and how strong one factor influences another ( 0 : no influence, 1: small/less than proportional, 2: middle/ proportional and 3: strong/stronger than proportional). These influences are represented by the so-called influence matrix (see Figure 10).

Adding directions to these influences ("+" means if factor A grows, factor B grows, too, and "-" means if A grows, B declines and vice versa) and graphically depicting these effects in a directed network chart generates the so-called effect system (see Figure 11).

Note that the determination of the strength of influence is not an exact science; thus, we want to give reasons for our influence assessment. For this reasoning, we clustered the factors of our model in accordance with Bjørn et al. [47] (pp. 78-79) into techno-spherefactors and eco-sphere factors. In addition to these two spheres, we suggest introducing a "socio-sphere" to cluster the socio-behavioral factors.

\subsubsection{Socio-Sphere Effects (Causes)}

The socio-sphere in our model shall represent the causes for urban traffic and logistics. With regard to the question whether activities are conducted from home (i.e., no physical traffic is generated) or not from home (i.e., physical traffic is generated), we defined three pairs of factors: classic office work/home office, classic leisure/home leisure, and classic shopping/online shopping.

All classic factors have a positive impact on sideway-, road-, and rail- traffic, but as induced traffic is split between the modes, we assessed the related impact strength with " +1 ", each. Reciprocally, we assessed the impact of home-based activities on these three forms of traffic with " -1 " as staying at home will reduce traffic. 


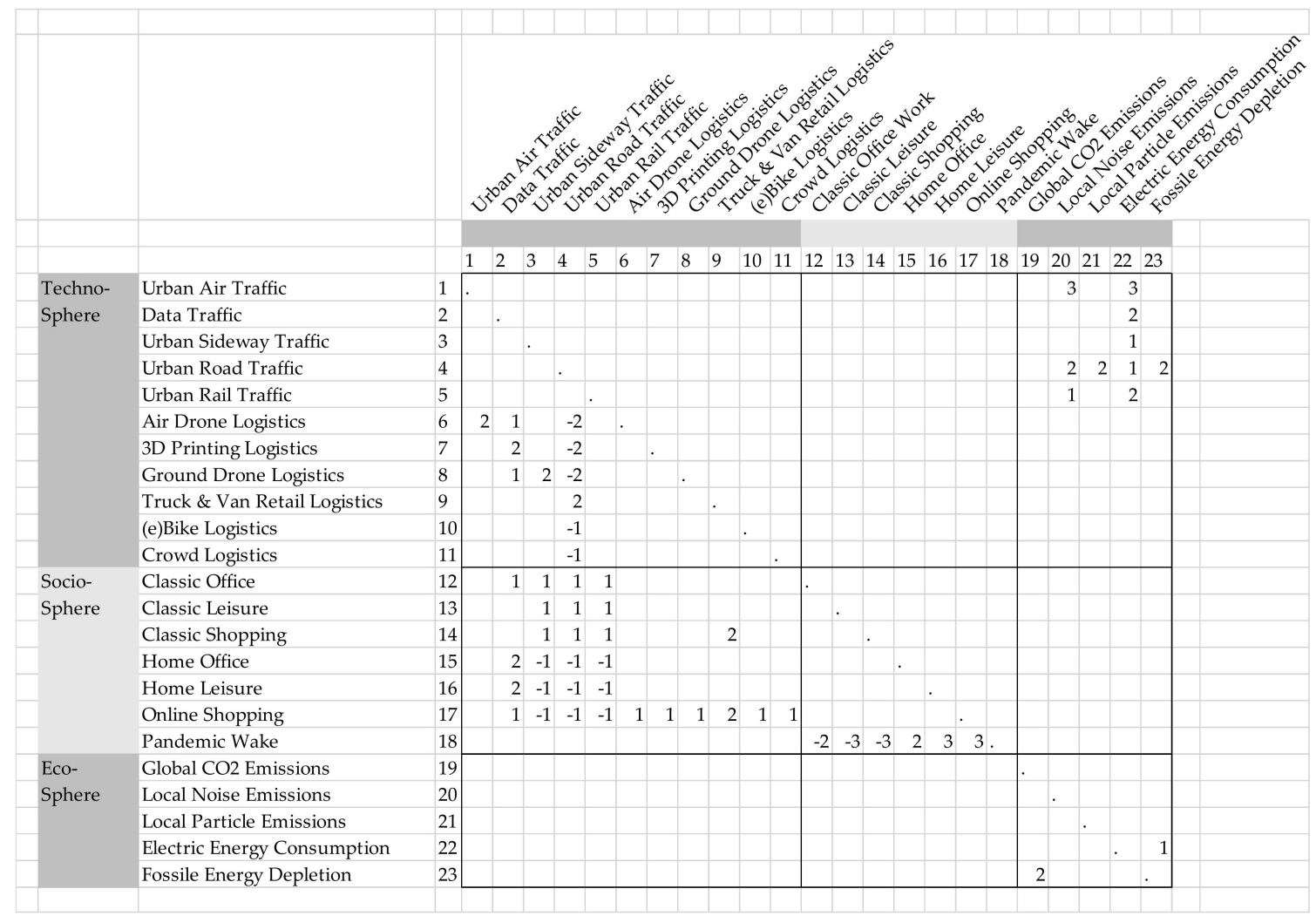

Figure 10. Influence matrix (enhanced by effect directions; zeros represented by empty spaces for transparency reasons).

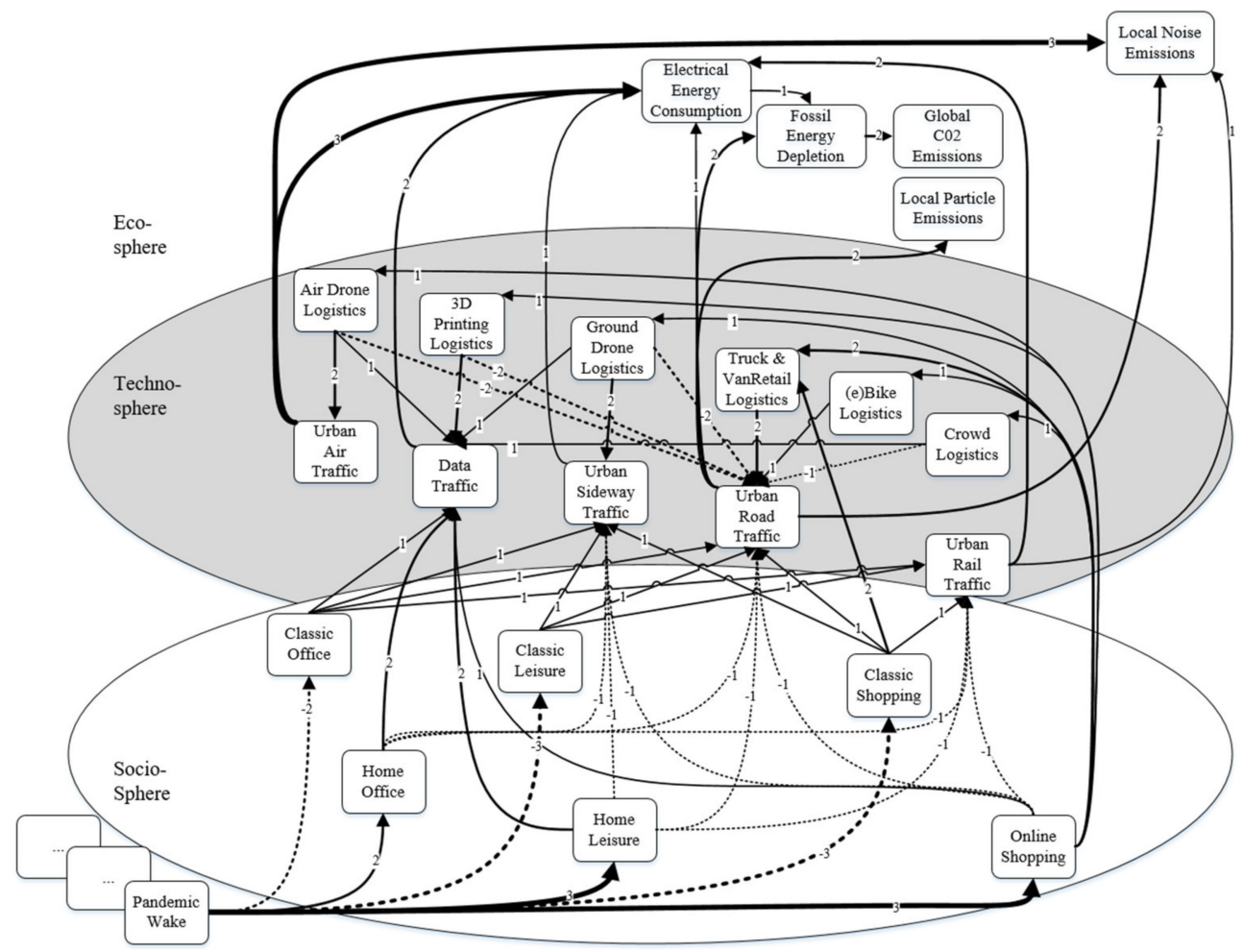

Figure 11. Effect system.

With respect to data traffic, we assumed that classic leisure and classic shopping have no significant impact on data traffic " 0 ". Online shopping and classic office work will generate moderate data traffic " +1 ", but home office will generate additional data traffic in 
comparison with classic office work, thus we rated the impact strength " +2 " in this case. As home leisure often includes streaming movies and playing online games, we assume that home leisure has a factor " +2 " on data traffic.

Our impact assessment on goods traffic (or logistics) was based on the following aspects. Classic shopping requires shop replenishments, which up to now is mostly fulfilled by truck- and van logistics " +2 ". Online shopping (not including click and collect models, which are represented by classical shopping in our model) requires home deliveries. Whilst today most home deliveries are performed by means of delivery vans $("+2$ "), the emerging goods transport services may also grow with online-shopping volumes (" +1 ") depending on the modal split.

Of the different potential factors which may influence the home-non-home-activity split in the socio-sphere, we picked one factor which currently implies major changes, which is the "pandemic wake" (driven by shutdown regulations as well as by personal fears to get infected with COVID-19). We assume that it has a strong positive effect on home leisure and online shopping " +3 " and a medium effect " +2 " on home office (because some work requires non-home-work, such as, e.g., in hospitals, and because some employers are reluctant to allow home offices). Reciprocally, the pandemic wake will reduce classical activities (" -3 " and " -2 ").

\subsubsection{Techno-Sphere Effects (Intermediators)}

Whereas the mobility needs of people (passengers) in our model have a direct impact on traffic, goods transport needs are mediated via logistics services concerning their effect on traffic. If logistics services grow, we assume that they will contribute linearly to the relevant traffic " +2 " with the following exceptions:

- Growing bike logistics will increase the number of bikes on roads, but it will not cause standing and obstructing road traffic (e.g., home delivery vans parked in second lanes). Thus, we rate the impact as small " +1 ".

- Crowd logistics will help to reduce existing road traffic " -1 " by partly shifting goods transports to other modes.

Air-, 3D-printing-, and ground-drone-logistics will help to significantly reduce urban road traffic by means of modal shift " -2 ", whereas crowd logistics will only partly reduce road traffic (because road traffic is one sub-option for crowd logistics execution)- thus we rate its effect on road traffic only as " 1 ".

On the other hand, air-drone, ground-drone- and crowd logistics will contribute to data traffic due to process monitoring and synchronization needs (" +1 ").

\subsubsection{Eco-Sphere Effects (Results)}

Finally, we assume that traffic contributes to resource depletion and urban emissions in our model as follows.

Electrical energy consumption is strongly affected by air-traffic (due to extra energy needs for take-off and hovering " +3 "). It is proportionally affected by data traffic and rail-traffic " +2 ". It is slightly affected by urban sideway traffic (i.e., ground drones " +1 ") and road traffic " +1 " (due to the current small part of road traffic which is electrically propelled).

Fossil energy depletion is partly driven by direct combustion in vehicles ("+2" from road traffic") and partly by electrical energy consumption (depending on the electricity mix-fossil, nuclear, regenerative " +1 "). Fossil energy depletion will also affect global $\mathrm{CO}_{2}$ emissions proportionally " +2 ".

Urban traffic-related local particle emissions are considered to be proportionally affected by road traffic, only " +2 ".

Last but not least, noise is a crucial factor for the well-being of urban citizens. Trafficrelated noise emissions today mostly stem from road traffic " +2 " and partially from nonunderground rail traffic (trams, suburban trains, mass rapid transit, etc., which operate on significantly less dense networks than road-networks and on scheduled intervals only, and 
thus contribute less to total urban noise emissions " +1 "). However, if air traffic becomes a significant part of urban traffic, it can be considered to be a strong additional urban noise emission source " +3 ", as there are almost no options for passive noise reduction constructions (which are widely in place for road and rail noise reduction in many urban contexts).

\section{Results}

The result of all the previously described steps is the effect system as depicted in Figure 11.

The resulting key insights of this approach can be summarized as follows: The introduction of data-traffic as a new modal concept has proven to have many and significant effect links to other model factors. Thus, it is a relevant factor in an urban transport effect system. Air traffic is just one of many new urban modal transport options. Its negative impacts on energy consumption and noise emissions are significant.

Insights from a methodology point of view are of another type of result. First of all, the application of Vester's (simplified) systems thinking approach has proven to be helpful to answer the research questions. The transfer of the eco-sphere and techno-sphere concept from life cycle assessment (LCA) to Vester's system thinking approach has proven to be helpful and has led to the establishment of a new sphere, the socio-sphere. The transfer of ecological impact factor categories from life cycle inventory (LCI) to Vester's system thinking approach has proven to contribute to the completeness assessment of environmental effects. The consequent (and falsifiable) definition of included and excluded impact factors helps to critically discuss and further develop the effect system model. A consequent differentiation between transport of passengers and transport of goods has helped to establish the need for an intermediate factor cluster, which we call "logistics services". This factor cluster moderates the impact of the demand for goods transport on goods traffic. A consequent differentiation between home activities and non-home activities has helped to model the impacts of the pandemic wake on traffic. Last but not least, the inclusion of noise as a significant emission factor is important-especially for the assessment of urban air traffic - even if this impact category is not represented by, e.g., the ReCiPe 2008 impact factor categories.

The interpretation of the effect system is given in the conclusion section. However, before we start with the interpretation, we want to critically discuss the used methodology and the results.

\section{Discussion}

Designing an integrated systems-thinking model for urban passenger and goods transport is a complex task. First of all, the underlying research questions have a significant impact on the choice of model elements. Secondly, the balance between model complexity and simplicity is a dilemma. Thus, the model and the implications of the model require critical discussion.

\subsection{Critical Discussion of Model}

The model and the methodology to generate this model are not the only possible options to answer the research questions. However, in a Popperian concept of science, both methodology and model together represent a tentative approach to solve the research questions, which may either be falsified by the scientific community or gain relevance, if falsification attempts fail.

\subsubsection{Model Elements (Factors)}

As we chose to build a qualitative top-level model, we needed to exclude certain factor clusters and factors. Especially leaving out costs and convenience as factor clusters was a major design decision. However, integration cost and convenience factors in the model would have resulted in a much higher model complexity which we wanted to avoid. Thus, 
adding cost and convenience factors to the model can be considered as a need for further research.

Within those factor clusters which we considered (i.e., social activities, traffic, logistics, and environmental impacts), we also had to choose which individual factors needed to be considered and which could be omitted (see discussion in Section 2). Still, these choices should critically be discussed by other scientists and, therefore, we see room for further research with regard to factor choice.

\subsubsection{Model Relations (Effects)}

A key challenge within systems-thinking modeling is the need to assess the effects between factors. Vester [44] (p. 230) phrases this task as follows: "The question is always this: If I change element A how strongly (in whichever direction) does element B change as a result of direct influence by A?" He then suggests to use the numbers 3 ("change a lot" / "disproportionally strong"), 2 ("more or less equally" / "proportionally"), 1 ("weak") and 0 ("no effect at all, a very weak effect or an effect occurring only after a lengthy delay" / "no connection") to indicate effect strength dimensions. This approach is helpful, but there is an inbuilt fuzziness in this approach, as there are no binary decision criteria on whether an effect strength is 3 or 2 or whether an effect strength is 1 or 0 . Thus, we argued in Section 2 why we assumed which effect strength and, hence, acknowledge the potential need for further critical discussion and research (especially, but not limited to the impact of air drones on noise emissions with regard to single unit noise emission vs. corridor noise emission as a function of distance, including its impact on human well-being and health in cities).

\subsection{Implications}

We see the following implications of our model for policymakers and regulatory bodies, lecturers and teachers, and researchers.

\subsubsection{Implications for Policymakers and Regulatory Bodies}

Policymakers, as well as regulatory bodies, need to make decisions. They decide which technologies shall be supported (e.g., by opening up regulatory frameworks for their use, or by granting subsidies) and how they shall be restricted (e.g., by setting regulative restrictions or by taxation). Concerning the opening of urban space for air drone traffic, the presented effect system shows the environmental mechanisms of such decisions. It also shows alternative decision options (e.g., support of data traffic or ground drone operations).

\subsubsection{Implications for Lecturers and Teachers}

The conception of traffic and transport is usually based on (or biased by) experience. New concepts of traffic and transport, by definition, show a lack of this experience element. Thus, models of traffic and transport that aim to create a better understanding of emerging and future developments and their effects are important. Therefore, it is an important contribution to put new concepts into a systems thinking model, because this approach helps to substitute missing experience.

\subsubsection{Implications for Researchers}

This non-quantitative piece of research unveiled some topical and conceptual issues that require further research.

First, we decided to leave out a significant number of influence factors in our model (see grey elements in figures of Section 2) to reduce complexity in our model. Thus, we see the need for further research in adding additional factors to the model. For instance, the ecological aspects of non-fossil resource depletion (e.g., rare earths and lithium) are affected by urban passenger and goods transport requirements on the one hand. On the other hand, these aspects are also influenced by emerging new means of transport (i.e., air drones, electrical vehicles, and data traffic), and thus may become more relevant in the 
nearer future. Therefore, the integration of non-fossil resource depletion into the model is desirable.

Second, urban low-altitude air traffic is likely to gradually come into existence. Whilst the general public can be considered to be mostly still unaware of this significant change, and policymakers can be considered to at least partly be influenced in their decisions by lobbyists, scientists working in the domains of ecology, traffic and transport, and acoustics should help to counterbalance this potentially lop-sided information situation.

Third, data transport and traffic as a potential partial substitute for passenger transport and traffic (see COVID-19 situation), as well as goods transport and traffic (see 3D-printing potentials), show potential for further research.

Fourth, there seems to be a need for further research on integrated traffic (and transport) models that integrate both passenger and goods traffic (and transport). Without refinement of these integrated models, it is difficult to assess concepts, which try to harvest the synergies from both worlds as, for example, crowd-logistics concepts. The introduction of logistics service model entities as we used them in our model may help to create better models for combined passenger and goods traffic.

\section{Conclusions}

The presented effect system helps to understand some significant interdependencies in urban traffic system evolution.

\subsection{Impacts of Changes in the Socio-Sphere}

Unsurprisingly, changes in the socio-sphere will change the demand for passenger and goods traffic. However, as can be seen by the example of the pandemic wake, these changes can be very strong. Thus, it makes sense to take into account whether the changes induced by the pandemic wake will remain, partially remain or evaporate. Further research is needed on whether there are (or might be) other socio-sphere factors with the potential to significantly change social behavior with respect to work, leisure, and shopping. Convenience-desire, which we explicitly omitted as a factor in our model, is one of these socio-sphere factors, but there may be others, too.

\subsection{Changes in the Techno-Sphere}

If cost and convenience aspects are omitted from a top-level perspective, passenger traffic directly depends on the existence and accessibility of passenger transport modes and the relevant demand from the socio-sphere.

However, goods traffic also depends on the available logistics services (which use the relevant transport modes and thus generate goods traffic). As legislative and regulative actions may hinder or support certain types of logistics services, their sustainability and ecological impacts should be considered by legislators especially as data-transfer (e.g., for $3 \mathrm{D}$ printing, teleworking, home leisure, etc.), ground-drones, eBikes, and crowd logistics are sustainable options to reduce road traffic without introducing air traffic.

\subsection{Impacts on the Eco-Sphere}

The impacts on selected elements of the eco-sphere are relatively simple to understand and strongly depend on the sustainability of the electrical energy generation (energy mix). However, air traffic especially is likely to have significant negative effects on the global environment due to missing bundling effects and additional energy consumption for takeoff and keeping airborne. Additionally, air-traffic noise emissions (without the option for noise protection walls) will most likely have a negative effect on urban life quality.

\subsection{Conceptual Insights}

As data traffic has the potential to partially substitute physical passenger and goods traffic under certain circumstances, data networks should conceptually be regarded as a new mode of transport that plays a role in the urban modal split. 


\subsection{The Matrix vs. The Fifth Element-Where Are We Heading?}

The propagation of air drones and air taxis as a new means of urban transport will bring us closer to a scenario as depicted in "The 5th element". Individual and commercial traffic will grow not only on roads but over the heads of citizens, too. Energy consumption and urban noise levels will rise.

On the other hand, the pandemic wake brings us closer to a scenario as depicted in "The matrix" - traffic is significantly reduced, our senses are fed not only by audio and video data, but by means of virtual reality, and our physical needs are met by home delivery services (including 3D printing). Still, this somehow frightening perspective will have a positive impact on our environment.

Author Contributions: Conceptualization: O.K. and F.F.; methodology: O.K. and F.F.; visualization: O.K.; writing — original draft, review and editing: O.K.; writing—review and editing: F.F. All authors have read and agreed to the published version of the manuscript.

Funding: The project on which this publication is based was funded by the Federal Ministry of Education and Research (BMBF) and the federal states within the framework of the "Innovative Hochschule" (IHS) program under the funding code 03IHS024C. The authors are responsible for the content of this publication. Das dieser Veröffentlichung zugrundeliegende Vorhaben wurde mit Mitteln des Bundesministeriums für Bildung und Forschung (BMBF) und den Ländern im Rahmen des Programms „Innovative Hochschule” (IHS) unter dem Förderkennzeichen 03IHS024C gefördert. Die Verantwortung für den Inhalt dieser Veröffentlichung liegt bei den Autoren.

Institutional Review Board Statement: Not applicable.

Informed Consent Statement: Not applicable.

Data Availability Statement: Data sharing not applicable. No new data were created or analyzed in this study. Data sharing is not applicable to this article.

Acknowledgments: The authors want to thank F. and M. Gumtau, as well as D. James for their valuable com-ments on the use of proper English. All remaining language imperfections are solely the re-sponsibility of the authors.

Conflicts of Interest: The authors declare no conflict of interest.

\section{References}

1. Taniguchi, E.; Thompson, R.G.; Yamada, T. New Opportunities and Challenges for City Logistics. Transp. Res. Procedia 2016, 12, 5-13. [CrossRef]

2. Silva, J.V.; Rezende, R.A. Additive Manufacturing and its future impact in logistics. IFAC Proc. Vol. 2013, 46, 277-282. [CrossRef]

3. Cerdas, F.; Juraschek, M.; Thiede, S.; Herrmann, C. Life Cycle Assessment of 3D Printed Products in a Distributed Manufacturing System. J. Ind. Ecol. 2017, 21, S80-S93. [CrossRef]

4. Publications Office of the European Union. U-Space Blueprint; SESAR Joint Undertaking: Luxembourg, 2017.

5. CORUS Consortium. U-Space: Concept of Operation. 2019. Available online: https://www.sesarju.eu/node/3411 (accessed on 1 March 2021).

6. Fu, M.; Rothfeld, R.; Antoniou, C. Exploring Preferences for Transportation Modes in an Urban Air Mobility Environment: Munich Case Study. Transp. Res. Rec. 2019, 2673, 427-442. [CrossRef]

7. Shamiyeh, M.; Rothfeld, R.; Hornung, M. A performance benchmark of recent personal air vehicle concepts for urban air mobility. In Proceedings of the 31st Congress of the International Council of the Aeronautical Sciences, Belo Horizonte, Brazil, 14 September 2018.

8. Vascik, P.D.; Hansman, R.J. Scaling Constraints for Urban Air Mobility Operations: Air Traffic Control, Ground Infrastructure, and Noise. In Proceedings of the 2018 Aviation Technology, Integration, and Operations Conference, Atlanta, GA, USA, 25-29 June 2018; AIAA AVIATION Forum. American Institute of Aeronautics and Astronautics: Reston, VA, USA, 2018. ISBN 9781624105562.

9. Carlsson, J.G.; Song, S. Coordinated Logistics with a Truck and a Drone. Manag. Sci. 2018, 64, 4052-4069. [CrossRef]

10. Scott, J.; Scott, C. Drone Delivery Models for Healthcare. In Proceedings of the 50th Hawaii International Conference on System Sciences, Big Island, HI, USA, 4-7 January 2017. [CrossRef]

11. Koiwanit, J. Analysis of environmental impacts of drone delivery on an online shopping system. Adv. Clim. Chang. Res. 2018, 9, 201-207. [CrossRef]

12. Figliozzi, M.A. Lifecycle modeling and assessment of unmanned aerial vehicles (Drones) CO 2 e emissions. Transp. Res. Part D Transp. Environ. 2017, 57, 251-261. [CrossRef]

13. Brand, P.; Dávila, J.D. Mobility innovation at the urban margins. City 2011, 15, 647-661. [CrossRef] 
14. Oviedo, D.; Guzman, L. Transportation Planning and Development in Bogotá. In The Routledge Handbook of Planning Megacities in the Global South; Rukmana, D., Ed.; Routledge: London, UK, 2020; ISBN 9780367223724.

15. Pils, M. Urbane Seilbahnen. In Digital Business für Verkehr und Mobilität-Ist die Zukunft Autonom und Digital? DB Institut für Digital Business der Johannes Kepler Universität Linz: Linz, Austria, 2020; ISBN 9783950463040.

16. Trummer, W.; Hafner, N.; Hofer, K.; Fellendorf, M.; Fallast, K.; Huber, G. New ropeway system for Smart Urban Mobility \& Logistics in the City of Graz. In Proceedings of the Transport Research Arena 2018: A Digital Era for Transport, Vienna, Austria, 16-19 April 2018.

17. Markvica, K.; Hu, B.; Prandtstetter, M.; Ritzinger, U.; Zajicek, J.; Berkowitsch, C.; Hauger, G.; Pfoser, S.; Berger, T.; Eitler, S.; et al. On the Development of a Sustainable and Fit-for-the-Future Transportation Network. Infrastructures 2018, 3, 23. [CrossRef]

18. Hansen, I.A. Hyperloop transport technology assessment and system analysis. Transp. Plan. Technol. 2020, 43, 803-820. [CrossRef]

19. Werner, M.; Eissing, K.; Langton, S. Shared Value Potential of Transporting Cargo via Hyperloop. Front. Built Environ. $2016,2,17$. [CrossRef]

20. Stein, D.; Schoesser, B. CargoCap-Transportation of Goods through Underground Pipelines: Research Project in Germany; American Society of Civil Engineers: Reston, VA, USA, 2012.

21. Visser, J.G. The development of underground freight transport: An overview. Tunn. Undergr. Space Technol. 2018, 80, 123-127. [CrossRef]

22. Hamburger Morgenpost. In diesen Stadtteilen kommen Corona-Tests per Roboter. Hamburger Morgenpost [Online]. 22 January 2021. Available online: https:/ / www.mopo.de/hamburg/jetzt-in-hamburg--in-diesen-stadtteilen-kommen-corona-tests-perroboter-37958166 (accessed on 1 March 2021).

23. Narayanan, S.; Chaniotakis, E.; Antoniou, C. Factors affecting traffic flow efficiency implications of connected and autonomous vehicles: A review and policy recommendations. In Policy Implications of Autonomous Vehicles; Milakis, D., van Wee, B., Thomopoulos, N., Eds.; Academic Press: Cambridge, MA, USA, 2020; ISBN 9780128201916.

24. Buldeo Rai, H.; Verlinde, S.; Merckx, J.; Macharis, C. Crowd logistics: An opportunity for more sustainable urban freight transport? Eur. Transp. Res. Rev. 2017, 9. [CrossRef]

25. Sampaio, A.; Savelsbergh, M.; Veelenturf, L.; van Woensel, T. Crowd-Based City Logistics. In Sustainable Transportation and Smart Logistics: Decision-Making Models and Solutions; Faulin, J., Grasman, S.E., Juan, A.A., Hirsch, P., Eds.; Elsevier: Amsterdam, The Netherlands, 2019; pp. 381-400. ISBN 9780128142424.

26. Crainic, T.G.; Montreuil, B. Physical Internet Enabled Hyperconnected City Logistics. Transp. Res. Procedia 2016, 12, 383-398. [CrossRef]

27. Banister, D. The sustainable mobility paradigm. Transp. Policy 2008, 15, 73-80. [CrossRef]

28. Banister, D. Cities, mobility and climate change. J. Transp. Geogr. 2011, 19, 1538-1546. [CrossRef]

29. Bertolini, L.; Le Clercq, F.; Kapoen, L. Sustainable accessibility: A conceptual framework to integrate transport and land use plan-making. Two test-applications in the Netherlands and a reflection on the way forward. Transp. Policy 2005, 12, 207-220. [CrossRef]

30. Bertolini, L.; Le Clercq, F. Urban Development without more Mobility by Car? Lessons from Amsterdam, a Multimodal Urban Region. Environ. Plan. A 2003, 35, 575-589. [CrossRef]

31. Kenworthy, J.R. The eco-city: Ten key transport and planning dimensions for sustainable city development. Environ. Urban. 2006, 18, 67-85. [CrossRef]

32. Wulfhorst, G.; Büttner, B.; Ji, C. The TUM Accessibility Atlas as a tool for supporting policies of sustainable mobility in metropolitan regions. Transp. Res. Part A Policy Pract. 2017, 104, 121-136. [CrossRef]

33. Pavone, M. Autonomous Mobility-on-Demand Systems for Future Urban Mobility. In Autonomes Fahren; Maurer, M., Gerdes, J.C., Lenz, B., Winner, H., Eds.; Springer: Berlin/Heidelberg, Germany, 2015; pp. 399-416. ISBN 978-3-662-45853-2.

34. Machado, C.; de Salles Hue, N.; Berssaneti, F.; Quintanilha, J. An Overview of Shared Mobility. Sustainability $2018,10,4342$. [CrossRef]

35. Priester, R.; Miramontes, M.; Wulfhorst, G. A Generic Code of Urban Mobility: How can Cities Drive Future Sustainable Development? Transp. Res. Procedia 2014, 4, 90-102. [CrossRef]

36. Kunze, O.; Wulfhorst, G.; Minner, S. Applying Systems Thinking to City Logistics: A Qualitative (and Quantitative) Approach to Model Interdependencies of Decisions by various Stakeholders and their Impact on City Logistics. Transp. Res. Procedia 2016, 12, 692-706. [CrossRef]

37. Kunze, O. Replicators, Ground Drones and Crowd Logistics A Vision of Urban Logistics in the Year 2030. Transp. Res. Procedia 2016, 19, 286-299. [CrossRef]

38. Melkonyan, A.; Koch, J.; Lohmar, F.; Kamath, V.; Munteanu, V.; Schmidt, A.; Bleischwitz, R. Integrated Urban Mobility Policies in Metropolitan Areas: A System Dynamics Approach for the Rhine-Ruhr metropolitan region in Germany. Sustain. Cities Soc. 2020, 102358. [CrossRef]

39. Fontoura, W.B.; Chaves, G.d.L.D.; Ribeiro, G.M. The Brazilian urban mobility policy: The impact in São Paulo transport system using system dynamics. Transp. Policy 2019, 73, 51-61. [CrossRef]

40. Del Vecchio, P.; Secundo, G.; Maruccia, Y.; Passiante, G. A system dynamic approach for the smart mobility of people: Implications in the age of big data. Technol. Forecast. Soc. Chang. 2019, 149, 119771. [CrossRef] 
41. Helbing, D.; Hennecke, A.; Shvetsov, V.; Treiber, M. MASTER: Macroscopic traffic simulation based on a gas-kinetic, non-local traffic model. Transp. Res. Part B Methodol. 2001, 35, 183-211. [CrossRef]

42. Doniec, A.; Mandiau, R.; Piechowiak, S.; Espié, S. A behavioral multi-agent model for road traffic simulation. Eng. Appl. Artif. Intell. 2008, 21, 1443-1454. [CrossRef]

43. Xia, F.; Rahim, A.; Kong, X.; Wang, M.; Cai, Y.; Wang, J. Modeling and Analysis of Large-Scale Urban Mobility for Green Transportation. IEEE Trans. Ind. Inf. 2018, 14, 1469-1481. [CrossRef]

44. Vester, F. The Art of Interconnected Thinking: Ideas and Tools for a New Approach to Tackling Complexity; Malik Management: München, Germany, 2007; ISBN 9783939314059.

45. Popper, K.R.; Camiller, P. All Life is Problem-Solving; Routledge: London, UK, 2001; ISBN 9780415249928.

46. Goedkoop, M.; Heijungs, R.; Huijbregts, M.; de Schryver, A.; Struijs, J.; van Zelm, R. ReCiPe 2008-A life Cycle Impact Assessment Method Which Comprises Harmonised Category Indicators at the Midpoint and the Endpoint Level: First Edition, Report I: Characterisation; Ministerie van VROM: Den Haag, The Netherlands, 2009.

47. Bjørn, A.; Owsianiak, M.; Laurent, A.; Olsen, S.I.; Corona, A.; Hauschild, M.Z. Scope Definition. In Life Cycle Assessment: Theory and Practice; Hauschild, M.Z., Rosenbaum, R.K., Olsen, S.I., Eds.; Springer: Cham, Switzerland, 2017; ISBN 9783319564746. 